\title{
DEVELOPING A CULTURE OF RADIATION PROTECTION IN THE HOSPITAL ENVIRONMENT
}

\author{
Julie Haglund* \\ Medical Physicist, Gothenburg, Sweden
}

\begin{abstract}
The responsibility of the radiation protection coordinator is to help ensure that radiation safety at the hospital is safeguarded in accordance with applicable laws and regulations. In practice, this means equipment registration and maintenance, personnel dosimetry, ensuring the competence of all employees who work with ionizing radiation, and documentation of all radiation protection measures and activities. This work describes the violations met and improvements made during one year of work as radiation protection coordinator at a regional hospital with locations in five different cities in Østfold County in Norway.
\end{abstract}

Key words: Radiation protection, radiation safety, ICRP 117, Østfold Hospital

DOI: $10.21175 /$ RadProc.2016.45

\section{INTRODUCTION}

According to national guidelines in Norway, the responsibility of the radiation protection coordinator at a hospital is to help ensure that radiation safety is safeguarded in accordance with applicable laws and regulations [1]. In practice, this means ensuring that equipment is registered and routinely maintained, personnel dosimetry, and ensuring the competence of all who work with ionizing radiation. Prior to 2015 , Østfold Hospital operated clinical activities in five different cities in Østfold County in Norway, and prior to 2012, the position of radiation protection coordinator was long absent.

In April 2012, the position of radiation protection coordinator was reestablished at Østfold Hospital due to pressure from the national radiation authority. In the organizational hierarchy of the hospital, the radiation protection coordinator was established as a leadership role in the radiology department, although responsibilities of the radiation protection coordinator stretched over the entire hospital in all departments where ionizing radiation was in use. This included the radiology department, but also interventional and surgical departments where mobile, c-arm equipment was used, as well as the emergency medical department, blood bank, angiography lab, and nuclear medicine department.

The establishment of authoritative communication within the hospital was necessary in order for the radiation protection coordinator to tackle responsibilities of the job. These tasks included equipment registration with the national radiation protection authority, personnel dosimetry, and personnel competence in radiation safety.

\section{ESTABLISHING AUTHORITATIVE COMMUNICATION}

For systematic and esthetic reasons, bringing the topic of radiation protection into focus was met with resistance. Systematically, placement of the radiation protection coordinator in the radiology department gave the impression of only local influence or importance. Communication with departments outside radiology was perceived as inappropriate and outside the realm of authority of the radiation protection coordinator. Even if everyone could appreciate the importance radiation protection as a theme, communication from someone from another department was not regarded as a priority. Due to mere habit, years of practice without attention to radiation protection, initial communication from the radiation protection coordinator to departments outside radiology was not appreciated.

In addition to an organizational placement that hindered authoritative communication of the radiation protection coordinator, Østfold Hospital operated clinical activities in five different cities. Email is easily sent and easily disregarded when the author not only comes from a different department but is also physically situated in a different city.

Bringing the topic of radiation protection into focus was met with resistance. Communication of a central coordinator to contact people in all departments is vital, and the first challenge of the job was to establish consistent and authoritative communication. Ionizing radiation was unwittingly being used in many departments, particularly in the form of c-arm equipment, yet the radiation protection coordinator was perceived as having no authority in departments outside radiology.

In order to remedy the communication difficulty, the hierarchy of the hospital was changed, and the radiation protection coordinator was organizationally 
placed under the administrative director of the hospital. Changing the organizational structure of the hospital and placing the coordinator under the administrative director improved the status of the coordinator and the message of radiation protection. Instead of a leader from the radiology department, the radiation protection coordinator was a figure of general authority in the organizational hierarchy of the hospital. This structure is, in fact, suggested by the national radiation protection authority: "The radiation protection coordinator should, in accordance with international recommendations, be given an independent position in the organization (staff function)" [2].

Consistent communication was established with at least one designated radiation protection contact person in each affected department, and it was thereby possible to address locally the issue of radiation safety competence. It was also decided that all radiation protection contact people should meet with the radiation protection coordinator at regular intervals, in perhaps biannual meetings, in order to discuss general and specific issues of radiation protection in the various departments. The first such meeting took place five months after the position of radiation protection coordinator was reestablished at Østfold Hospital, and in keeping with the desire to establish approximately biannual meetings, the second meeting took place five months after the first meeting.

\section{Competence of Personnel}

National guidelines recommend that all employees who use or are in contact with ionizing radiation complete some form of yearly education about radiation safety: "Personnel shall be annually trained in relevant radiation safety and radiation use according to their working methods and individual tasks. All affected personnel must have equipment-specific training, including factors affecting radiation dose and image quality" [2].

Records of this training were sparse or absent in every department of the hospital. Without documentation, despite actions which may or may not have occurred, national guidelines cannot be fulfilled. It was necessary for the radiation protection coordinator to create and deliver radiation safety lectures, tailored both to the radiology department and to other departments. The lectures for the radiology department were more detailed, as radiographers and radiologists are or should already be competent in radiation safety. Lectures for other departments, such as surgical and interventional laboratories, were specific to their equipment and exposure situations.

Equipment specific training outside the radiology department was accomplished by giving practical lessons to the radiation protection contact person in departments where c-arm, mobile x-ray equipment was used and by creating a simple, pocket guide to the basic features of the c-arm. Initially, the radiation protection coordinator gave lessons in small groups to employees in surgical and interventional departments, demonstrating basic features of the c-arm and radiation safety practices. The contact person of each department was trained in this way by the radiation protection coordinator and was then responsible for future training of employees in their departments, as well as for distributing the pocket guide or making it available.

The most critical task of giving lectures was ensuring that every employee who attended a radiation safety lecture signed a registration paper. The radiation protection coordinator and leader of the department kept copies of this registration paper, as required by national guidelines. If the national radiation authority should visit the hospital for an inspection, it was possible to produce proof that employees had received recent training in radiation protection. It is noted that there was no test of knowledge after the lectures, and only attendance was required.

In addition to classroom lectures, electronic courses were created in the hospital's electronic learning platform so that employees could refresh their knowledge of radiation safety whenever they had time. Like classroom lectures, electronic courses were tailored to two groups, employees with an educational background in radiology and those outside the radiology department. Due to the electronic nature of the system, a record was created of each employee who completed an electronic course. No test of knowledge followed the electronic courses, but they were interactive, and the radiation protection coordinator decided that all affected employees should complete both a live, classroom lecture and the corresponding electronic course.

\section{DOSIMETRY}

National guidelines require that employees working within a controlled or supervised area get their personal radiation exposure determined, and that the employee will contribute to this [2]. In the radiology and nuclear medicine departments, personal TLD dosimeters were a standard part of the working uniform of employees, and routines were place for maintaining the use of the dosimeters and records of employee exposures. Outside radiology, however, the use of personal dosimeters was not consistent or altogether absent. This fact was not unique to Østfold Hospital, but is documented by the ICRP: "In spite of the requirement for individual monitoring, the lack of use or irregular use of personal dosimeters is still one of the main problems in many hospitals" [4].

Reasons for the inconsistent use of personal dosimeters outside the radiology department included changes in technology, traditions of practice, and education.

Technology and the use of technology evolve faster than ethical considerations and regulations. The radiation protection coordinator at Østfold Hospital discovered that medical professionals are briefly introduced to new equipment, but details about how it works and the dangers behind it quickly fade in comparison to the clinical benefits

When told that medical professionals who use carm, mobile x-ray equipment must wear personal dosimeters, opposition came in the form of economic arguments. The cost of dosimeters was thought to be extravagant, it was believed that the cost of dosimeters would limit clinical activities, and that it would be necessary to hire additional personnel solely for organizing the use of personal dosimeters. In the 
radiology department, dosimeters were routinely used for years without these burdens.

Some professionals were not able to identify the $\mathrm{x}$ ray tube from the image intensifier, despite being authorized to use c-arm equipment in the laboratories of the hospital. Arguments against the use of dosimeters were also based on old measurements that had been made with dosimeters, but the measurements were not skillfully performed. A dosimeter that was hung behind the c-arm received no dose, and a dosimeter that was placed on the anesthesia cart received little dose. These were used in order to justify abandonment of personal dosimeters by all employees, despite the fact that few, if any, employees stand behind the c-arm during clinical practice. In another laboratory, only four dosimeters were available, and they were not used or were hung on the anesthesia cart instead of being used for clever and insightful measurements that reflect actual employee exposures.

Radiation was found to have a different status outside the radiology department. In specialization education for gastroenterological surgery, for example, radiation protection is not an obligatory theme for any class. The specialist committee views it as important, but they mean that the responsibility for sufficient education in radiation protection lies on the owner of the hospital, equivalent to education about fire hazards.

Even in the radiology department, the registration of patient doses was not consistent at Østfold Hospital. In one city, radiographers were diligent in recording the dose. In a different city, the traditions were not the same, and employees thought it was a burden to make a few clicks of the mouse and enter the patient dose electronically. It was a task of the radiation protection coordinator to emphasize the requirement to register patient doses. According to national guidelines for diagnostic procedures, for exam types like CT, angiography and intervention, conventional X-ray gastro, and exams of children: "Individual registration of radiation exposure to the patient shall be made in the patient's medical records or otherwise obtainable" [1].

\section{DOCUMENTATION}

Due to the long absence of a radiation protection coordinator at Østfold Hospital, documentation relating to radiation safety was sparse and outdated. Of primary interest was documentation related to the competence of personnel with respect to radiation safety, records of personnel dosimetry, and the registration of equipment and routine quality controls of the equipment. Without documentation, the hospital had nothing to present to the national radiation protection authority if an inspection should occur. The radiation protection coordinator decided to create an electronic central file area in the hospital's computer server for storing records of everything related to radiation protection and radiation safety at the hospital.

The national radiaiton protection authority in Norway maintains an electronic portal where all equipment and sources of ionizing radiation are recorded. It is the job of the radiation protection coordinator at the hospital to maintain this portal.
When the radiation protection coordinator role was revised at Østfold Hospital in April 2012, information in the national portal about equipment and sources was outdated. It was necessary to contact every department where radiological equipment had been located in order to determine whether the equipment was still in place, had been removed, or if new equipment or sources had come into use. Since the hospital operated clinical activities in five different cities, it was not simply to walk around one hospital and count machines, but to take contact with leaders of departments throughout the entire region, as well as medical technical personnel, in order to determine what equipment actually existed at the hospital.

In addition to national records of equipment, legislation requires that radiological equipment receive annual quality controls $[1,2]$. Physicists who visited the hospital in order to perform quality controls did write reports about their work. A copy of these reports was made and stored in the central file created by the radiation protection coordinator in order to improve access to all documentation related to radiation safety. It must be noted that physicists visited the hospital in order to perform quality controls, and none were employed, at that time, by Østfold Hospital itself. Their services were hired from hospitals in Oslo, thus possibly hindering access to quality control reports. By storing a copy in the server of Østfold Hospital, national regulations were surely fulfilled.

Included in the quality control of equipment were lead aprons worn as radiation protection in various departments. Records of maintenance of the lead aprons were sparse in the radiology department and absent in other departments. It was necessary to perform a quality control of all lead aprons as well as to establish routines for subsequent, yearly quality controls. A simple checksheet was created in order to document what specific lead apron was controlled, in what department it was located, and any notes about the quality of the lead apron, such as tears or holes. A copy of the checksheet was stored electronically in the file server created by the radiation protection coordinator as well as locally in the department.

\section{CONCLUSIONS}

Adhering to national radiation safety laws at a hospital requires a central radiation protection coordinator who is consistently in place to maintain contact with the national radiation authority, to keep current records of all radiation protection activities at the hospital, and to drive an internal educational system. At Østfold Hospital, success was achieved by reorganizing the hospital hierarchy such that the radiation protection coordinator was independent of any department and had authority under the administrative director. Contact was then reestablished locally in every department that uses ionizing radiation. Focus on radiation safety was accomplished by creating e-learning classes, giving classroom lectures to every department where ionizing radiation is used, and educating contact people to give equipment specific training in their departments. Of central importance in any work is documentation, and a central file was created in the internal computer system of the hospital in order to store classroom 
lectures, educational articles of interest, and equipment maintenance records.

Acknowledgement: The content of this work is solely the responsibility of the author, who is not currently employed by or affiliated with Østfold Hospital at the time of publication of this work.

\section{REFERENCES}

1. Helse- og omsorgsdepartementet. (Oct. 29, 2010). FOR 2010-10-29-1380, Forskrift om strålevern og bruk av stråling [Royal Norwegian Ministry of Health and Care Services. (Oct. 29, 2010). FOR-2010-10-29-1380, Act on Radiation Protection and Use of Radiation.]
2. E.G. Widmark et al., Veileder om medisinsk bruk av røntgen- og MR-apparatur: Veileder til forskrift om strålevern og bruk av stråling, Veileder nr. 5, Statens strålevern, 2005. Revidert Sep. 2014. (E.G. Widmark et al., Guidance for use of medical X-ray and $M R$ equipment: Guidance to Regulations for radiation protection and use of radiation, Guidance no. 5, Norw. Rad. Prot. Auth., 2005. Revised Sep. 2014

3. Helse- og omsorgsdepartementet (12.05.2000). LOV200o-05-12-36 Lov om strålevern og bruk av stråling [strålevernloven]. [Royal Norwegian Ministry of Health and Care Services. (May 12, 2000). LOV-20OO-O5-12-36 Law on Radiation Protection and Use of Radiation.]

4. M.M. Rehani et al., "ICRP Publication 117: Radiological Protection in Fluoroscopically Guided Procedures Performed Outside the Imaging Department," Annals of the ICRP, vol. 40, no. 6, pp. 1-102, Dec. 2010 